\title{
How to promote fruit consumption in children: visual appeal versus restriction
}

Citation for published version (APA):

Jansen, E., Mulkens, S., \& Jansen, A. T. M. (2010). How to promote fruit consumption in children: visual appeal versus restriction. Appetite, 54(3), 599-602. https://doi.org/10.1016/j.appet.2010.02.012

Document status and date:

Published: 01/01/2010

DOI:

10.1016/j.appet.2010.02.012

Document Version:

Publisher's PDF, also known as Version of record

Document license:

Taverne

Please check the document version of this publication:

- A submitted manuscript is the version of the article upon submission and before peer-review. There can be important differences between the submitted version and the official published version of record.

People interested in the research are advised to contact the author for the final version of the publication, or visit the DOI to the publisher's website.

- The final author version and the galley proof are versions of the publication after peer review.

- The final published version features the final layout of the paper including the volume, issue and page numbers.

Link to publication

\footnotetext{
General rights rights.

- You may freely distribute the URL identifying the publication in the public portal. please follow below link for the End User Agreement:

www.umlib.nl/taverne-license

Take down policy

If you believe that this document breaches copyright please contact us at:

repository@maastrichtuniversity.nl

providing details and we will investigate your claim.
}

Copyright and moral rights for the publications made accessible in the public portal are retained by the authors and/or other copyright owners and it is a condition of accessing publications that users recognise and abide by the legal requirements associated with these

- Users may download and print one copy of any publication from the public portal for the purpose of private study or research.

- You may not further distribute the material or use it for any profit-making activity or commercial gain

If the publication is distributed under the terms of Article $25 \mathrm{fa}$ of the Dutch Copyright Act, indicated by the "Taverne" license above, 


\title{
Short communication
}

\section{How to promote fruit consumption in children. Visual appeal versus restriction ${ }^{\text {is }}$}

\author{
Esther Jansen *, Sandra Mulkens, Anita Jansen \\ Maastricht University, Faculty of Psychology and Neuroscience, Department of Clinical Psychological Science, P.O. Box 616, 6200 MD, Maastricht, The Netherlands
}

\section{A R T I C L E I N F O}

\section{Article history:}

Received 2 February 2010

Received in revised form 12 February 2010

Accepted 15 February 2010

\section{Keywords:}

Childhood obesity

Fruit consumption

Restriction

Visual appeal

\begin{abstract}
A B S T R A C T
The prevalence of overweight is increasing dramatically in children. A protective factor against the development of overweight is a sufficient intake of fruit and vegetables. However, the consumption of fruit and vegetables in children is far from ideal these days. Therefore, it is important to examine how the intake of fruit and vegetables can be promoted. In this study, the effects of two fruit promoting techniques were evaluated in 4-7-year-old children: presenting fruit in a more visually appealing manner versus restricting the intake of fruit. Two presentations of fruit (regular and visually appealing) were offered to the participants. In a first taste session participants were either allowed to eat from both fruit presentations (no-prohibition group) or prohibited from eating one of the two presentations (regular fruit prohibited group/visually appealing fruit prohibited group). In a second taste session all participants were allowed to eat from both fruit presentations. The results indicated that visual appeal had a strong effect on consumption of the fruit. With respect to restriction, no effects were found. Parents, schools, supermarkets and food producers should take advantage of these results, and offer children fruit and vegetables that are presented in a visually appealing manner.
\end{abstract}

(c) 2010 Elsevier Ltd. All rights reserved.

\section{Introduction}

Obesity and overweight are sizeable health threats. Among children, the prevalence of weight problems has increased to exceptional proportions. Currently, one out of seven Dutch children is overweight (van den Hurk et al., 2006) whereas 3\% of the Dutch children are obese. These numbers are alarming in light of the grave consequences of overweight and obesity. Besides genetic factors, environmental factors play a key role in the development of obesity. In our modern western society we are constantly surrounded by unlimited amounts of unhealthy kinds of food in all varieties and, above all, vast portions. In addition, physical exercise is not promoted. This so-called 'obesogenic' environment is put forward as a major factor in the development of obesity (Guerrieri, 2005). Besides the influence of our current society, children's eating behaviours are strongly affected by their parents. Parents do not only serve as role models for their offspring (Brown \& Ogden, 2004), they are also responsible for purchasing groceries and doing most of the cooking. On top of that, parents influence their children's food preferences and intake by using

\footnotetext{
The authors would like to thank Tessa van den Bergh, Jeanette Bisschops, Goele Bollen, Andrea Klefoth, Sanne Peeters, Lieze Poesen, Felix Sion and Shabnam Sippas for their help in data acquisition.

* Corresponding author.

E-mail address: elgmjansen@live.com (E. Jansen).
}

control techniques like restriction of intake and pressure to eat (Birch et al., 2001).

In order to tackle the obesity problem it is not only important to put the brakes on unhealthy eating behaviours, but also to promote healthy eating behaviours, like fruit and vegetable intake. Fruit and vegetables have positive influences on our health. For instance with respect to the prevention of cardiovascular disease, the beneficial effect of fruit intake has been proven (Hung et al., 2004). In addition, fruit also protects against overweight (Epstein et al., 2001; McCrory et al., 1999; Roblin, 2007). Therefore, it seems selfevident to examine how their intake can be increased. Current food patterns indicate that children do not consume enough fruit and vegetables. Even though the Dutch National Food Council recommends that children eat at least two portions of fruit a day (Health-Council-of-the-Netherlands, 2002), Dutch children eat in fact less than one portion of fruit a day on average (Dutch Food Consumption Survey, 1998).

Now, the crucial question is how to encourage children to eat more fruit. For many parents, a chosen method seems to be pressuring their children to eat them. However, previous research has demonstrated that pressuring children to eat healthy foods results in adverse effects: children in fact eat less fruit and vegetables when they are forced to eat them. In addition they may become picky eaters (Galloway, Fiorito, Lee, \& Birch, 2005).

When we take a closer look at the attractiveness of sweets again, children's strong attraction to sweets might partly result from the fact that the intake of sweets is often restricted. Earlier research has already shown that not only the restriction of sweets 
leads to higher intake in children (Jansen, Mulkens, \& Jansen, 2007), the restriction of fruit yields similar effects (Jansen, Mulkens, Emond, \& Jansen, 2008). In this latter study, the intake of either fruit or sweets was prohibited during a first taste session. A third (control) group received no prohibition during this first taste session. In a second taste session, the prohibitions were removed, and all participants could eat both sweets and fruit. It was found that both the restriction of sweets and fruit during the first taste session led to an increase in intake of the respective forbidden food during the second taste session, as opposed to the control group. Therefore, prohibiting the intake of fruit was one of the promotion techniques that were examined during the current study. It was hypothesized that children would eat more fruit when the taste session had been preceded by a prohibition to eat the presented fruit.

Next, availability (whether the food is present) and accessibility (e.g. form) of fruit were found to facilitate its consumption (Hearn et al., 1998). Bönnhoff, Eissing, Baumann, and Kuß (2002) examined whether the accessibility of fruit and vegetables could increase the intake in children. They presented children with different kinds of fruit and vegetables (apples, bananas and carrots) in two different forms: the control group received whole raw and washed fruit and vegetables; the experimental group received cut up pieces of the same fruit and vegetables. It was found that children in the experimental group ate almost twice as much fruit and vegetables as opposed to children in the control group. It was concluded that children will eat more fruit and vegetables if these are easier to consume.

Visual appeal falls outside the scope of accessibility, but is expected to influence consumption positively as well. For instance, the majority of all sweets are visually appealing, for example by their colour or shape. Fruit consumption in children is expected to increase when the presented fruit is made more visually appealing. The second promotion technique that was examined in the current study therefore was manipulating the visual appeal of fruit. Finally, an interaction between restriction and visual attractiveness was expected. That is, it was hypothesized that the largest increase in fruit consumption would occur in the group were the visually appealing fruit was prohibited before.

\section{Method}

\section{Participants}

Ninety-four children were recruited from six primary schools in The Netherlands and Belgium. Parents of children in primary school were approached by means of a letter and invited to let their children participate in the current study. Participants were told that the experimenter was interested in what kind of fruit children like. The participating children were 4-7-year olds (mean age $=5.48, \mathrm{SD}=.58$ ). In this age group, minimal social desirable behaviour concerning eating was expected. In addition, children of this age category are able to obey prohibitions (Piaget, 1965). Permission was obtained from the participating schools as well as from the children's parents. Parents were requested not to share information concerning the content of the study with their children. The study was approved by the ethical committee of the Faculty of Psychology and Neuroscience, Maastricht University. Cooperating schools received a gift certificate afterwards.

\section{Design}

The experiment consisted of two phases. During phase 1 participants were presented with both fruit types (visually appealing and regular). There were three groups (participants were randomly assigned to one of the three groups): in one they were allowed to taste from both types of fruit (no-prohibition group) whereas in the other two conditions they were told not to eat either the visually appealing or regular fruit (visually appealing fruit prohibition group and regular fruit prohibition group). This was followed by phase two in which all participants could freely eat from both fruit types. Dependant variables were regular fruit intake in grams, visually appealing fruit intake in grams and desire for the prohibited food.

\section{Measurements}

\section{Fruit}

In a pilot study, 30 children were asked to name their favourite kind of fruit. The three kinds of fruit mentioned most often in this pilot study were used in the main study. By doing so, we tried to make sure that every participant had a taste for at least one kind of fruit that would be presented. Seedless grapes ( $175 \mathrm{~g} /$ presentation), apple pieces (125 g/presentation) and strawberries ( $150 \mathrm{~g} /$ presentation) were presented to the children. These three kinds of fruit were presented in two different ways and offered to the participants simultaneously. The 'visually appealing' fruit was a mix of the above-mentioned fruits, pierced with flagged cocktail sticks and stuck into a watermelon. The 'regular' fruit was an identical mix of these fruits, simply offered on a white plate. To rule out any differences concerning the time children would need to consume the different presentations of fruit, the fruit in the 'regular' presentation was also skewered, but presented with a regular cocktail stick. In all 3 the conditions and in both phases, both the 'regular' fruit and the 'visually appealing' fruit were presented.

\section{Desire to eat, tastiness and satiety}

To measure the desire to eat a particular kind of fruit, a five point rating scale ranging from 0 ('no desire to eat at all') to 4 ('a very large desire') was used. Tastiness of the different kinds of fruit was measured with a 10 point rating scale ranging from 1 ('not tasty at all') to 10 ('very tasty'). Finally, satiety was measured with a Visual Analogue Scale (marking the left extremity meaning 'their tummy was totally empty and marking the right extremity meaning 'their tummy was completely full'). Tastiness and satiety were measured before phase 1 to assure the participants from the different groups did not differ in their taste ratings and were equally satiated before the experiment started. Desire was assessed at two moments: before phase 1 and after phase 1 .

\section{Procedure}

All children were tested individually. They were picked up from their class rooms and asked to sit down in a quiet room without any distracters. The experimenter then introduced him/herself and told the child that he/she would have to answer various questions and taste different kinds of food. The actual experiment then began. The two presentations of fruit were placed in front of the participant. Current levels of satiety, tastiness and desire for all to be presented foods were assessed. Then the first taste session started, during which the child was left alone. During this first taste session, participants in the 'regular fruit prohibition group' were prohibited from eating fruit from the regular presentation, whereas they were allowed to eat as much as they wanted from the visually appealing presentation. This was precisely the other way around for participants in the 'visually appealing fruit prohibition group'. Children in the no-prohibition group were allowed to eat fruit from both the regular and the visually attractive presentation. After $5 \mathrm{~min}$, the experimenter returned and took away the food, which was weighed in another room. Levels of desire for the different kinds of fruit were then assessed. Next, the second phase started. During this phase, all participants 
received the same instructions: they could eat as much fruit as they liked from both the regular and the visually appealing presentation. After $5 \mathrm{~min}$, the experimenter returned and took the food away. Again, the fruit was weighed outside the room. The child then returned to the classroom. Parents received a debriefing letter about the experiment afterwards.

\section{Results}

Data for all 94 children were used in the reported analyses. ${ }^{1}$ One way ANOVAs showed no group differences with respect to desire, tastiness and satiety ratings before phase 1 .

Hypothesis 1. Children in the 'regular fruit prohibition group' will show an increased desire for the regular fruit and will consume more regular fruit during phase 2 as compared to the other two groups

Difference scores for desire for regular fruit were calculated (desire after prohibition phase minus desire at start experiment). To test this first hypothesis (the pure effect of restriction), a MANOVA (difference score for desire for regular fruit and intake of regular fruit in phase 2 as dependent variables, group as factor) was carried out. No significant differences between the three groups were found with respect to desire. Desire for regular fruit actually decreased slightly in all groups (mean $=-.32(\mathrm{SD}=.98)$ for the 'regular fruit prohibition group' versus mean $=-.25(\mathrm{SD}=.78)$ for the 'no-prohibition group' and mean $=-.23(\mathrm{SD}=.91)$ for the 'visually appealing fruit prohibition group'). With respect to the intake of regular fruit in phase 2 , no differences were found (23.30 $\mathrm{g}(\mathrm{SD}=26.97)$ for the 'regular fruit prohibition group' versus $34.03 \mathrm{~g}(\mathrm{SD}=37.51)$ for the 'no-prohibition group' and $21.66 \mathrm{~g}$ $(S D=24.15)$ for the 'visually appealing fruit prohibition group').

Hypothesis 2. The intake of visually appealing fruit will be larger than the intake of regular fruit.

To test this hypothesis, the data of participants in the noprohibition condition alone were analysed, as we wanted to examine the pure effect of visual appeal (e.g. without the potential effects of prohibition). A paired sample $t$-test was carried out, with total intake of regular fruit (phase 1 and 2 added up) and total intake of visually appealing fruit (phase 1 and 2 added up) as the paired variables. The results showed a significant effect of visual appeal on intake $(t(35)=3.69, p=.001)$. As expected, the total intake of the visually appealing fruit was larger than the intake of regular fruit $($ mean $=135.37 \mathrm{~g}(\mathrm{SD}=78.64)$ versus mean $=73.34 \mathrm{~g}$ $(\mathrm{SD}=67.24))$.

Hypothesis 3. Children in the 'visually appealing fruit prohibition group' will show an increased desire for the visually appealing fruit and will consume more visually appealing fruit during phase 2 as compared to the other two groups.

Difference scores for desire for visually appealing fruit were calculated (desire after prohibition phase minus desire at start experiment). To test the third hypothesis (interaction effect of visual appeal and restriction) a MANOVA (difference score for desire for visually appealing fruit and intake of visually appealing fruit in phase 2 as dependent variables, group as factor) was carried out. Regarding desire, no significant differences between the three groups were found. (mean $=-.17(\mathrm{SD}=.76)$ for the 'visually appealing fruit prohibition group' versus mean $=-.06$ $(\mathrm{SD}=1.18)$ for the 'no-prohibition group' and mean $=-.18$

\footnotetext{
${ }^{1}$ When participants who did not comply with the instructions of the experimenter $(n=11)$ were excluded from the analyses, the reported findings were not affected. Therefore, the analyses with all 94 participants were reported.
}

( $\mathrm{SD}=1.34)$ for the 'regular fruit prohibition group'). With respect to the intake of visually appealing fruit in phase 2 , no differences were found ( $63.31 \mathrm{~g}(\mathrm{SD}=43.73)$ for the 'visually appealing fruit prohibition group' versus $62.60 \mathrm{~g}(\mathrm{SD}=53.93)$ for the 'no-prohibition group' and $70.97 \mathrm{~g}(\mathrm{SD}=59.50)$ for the 'regular fruit prohibition group').

\section{Discussion}

The aim of the current study was to examine how fruit consumption in children may be increased. Two different promotion techniques were evaluated: prohibiting the fruit prior to the actual intake and presenting fruit in a more visually appealing manner. To this end, ninety-four 4-7-year-old children participated in a taste experiment in which they were either prohibited from eating regular fruit, prohibited from eating visually appealing fruit or not prohibited at all. A second taste session followed, during which the earlier imposed prohibitions were no longer operative.

Children were expected to consume more fruit when the taste session had been preceded by a prohibition to eat fruit. However, the data do not support any influence of restriction on subsequent fruit intake.

Secondly, it was hypothesized that children would consume more fruit when it was presented in a visually appealing manner. The consumption of visually appealing fruit was indeed significantly larger than the consumption of regular fruit: children ate nearly twice as much of the visually appealing fruit mix as opposed to the regular fruit mix. From these data it can be concluded that presenting fruit in a more visually appealing manner actually promotes fruit consumption in children.

Finally, an interaction effect of visual appeal and restriction was expected. However, there was no support for an interaction effect of restriction and visual appeal in the current study.

In general, the current study found support for a main effect of visual appeal on intake, whereas restriction was not supported as a promotion technique. A limitation of the current study is that where intake data evidently show the promoting effect of visual appeal on intake, this is not supported by desire scores; the desire for visually appealing fruit scores do not differ from desire for regular fruit scores. That could implicate that the use of desire rating scales is not suitable for young children. However, these desire ratings were successfully used before in a comparable age group (Jansen et al., 2007). Another possibility is that, because there were only 5 rating options (0-4), there was not enough dispersion of the scores to result in significant differences.

It was assumed that the way in which the fruit was presented was visually appealing to the children. A limitation of the study is that there is no actual evidence to support this assumption. It seems likely that the presentation of the fruit was indeed visually appealing, but it is possible that factors other than visual appeal (for example novelty) could be operating. As it cannot be stated that the effects on intake can be solely attributed to visual appeal, this term should be nuanced into for example 'manner of presentation'.

There was no indication from debriefing the children why they ate more in the 'visually attractive' than the regular fruit condition. They knew very well that both fruit presentations tasted identical, but still they consumed more from the 'visually attractive' fruit. Perhaps it was not about taste, but about fun. Even though the effect of presentation manner cannot be explained, the promoting effect of presentation on fruit consumption seems rather logical. When children (or people in general) can choose between two options it seems quite obvious that they choose the (visually) most attractive option. The effect of manner of presentation on fruit consumption 
appears to be a rather robust effect. Implications of this finding seem quite simple. Parents should present fruit in a more appealing manner in order to stimulate their consumption in their children. In addition, food producers, schools and supermarkets can take an active part in developing and proffering more appealing alternatives. A number of Dutch chains of supermarkets recently introduced the so-called 'snack fruits'; bite-size raw vegetables or pieces of fruit in an attractive packaging. Although these healthy snacks are not especially developed for children, it is certainly a valuable initiative. Perhaps adding a little toy (like the toy that comes with a happy meal) to the packaging could make this kind of snack even more appealing. On the other hand, it cannot be predicted for how long a new, more (visually) appealing presentation of fruit remains interesting for children. When children are exposed to a new kind of fruit presentation for a number of times, they might lose their interest in the fruit. Therefore, in the long term, it is probably necessary for parents and food producers to remain innovative. Future research should focus on evaluating other methods that can be used to make fruit more appealing. In addition, future research should also focus on whether the consumption of vegetables could be increased in a similar way, as vegetables are generally less liked than fruit.

With respect to restriction as a method to promote consumption, more research is recommended as well. As mentioned before, earlier research did find effects of restriction on subsequent fruit intake (Jansen et al., 2008). There are no evident explanations for the restriction effect failing to occur in the current study, as the design of both studies is of the same kind. One possible influence could be that children in the Jansen and colleagues study had to chose between fruit and a completely different alternative (sweets), whereas in the current study both options were identical in taste. In the Jansen et al's. (2008) study, children had not experienced the taste of the fruit yet, whereas in the current study, children had already tasted the fruit (although in a different presentation). Even though no effects of restriction on fruit intake were found in the current study, it cannot be ruled out that restriction does not have any influence at all. Future research will have to provide us with a definite answer on the role of restriction. Restriction as a promotion strategy would be the less preferable option anyway, as parents may experience resistance in prohibit- ing their children to eat healthy foods, even if there is evidence that it increases the intake of these foods eventually. Presenting fruit in an attractive manner is a more convincing strategy to promote fruit consumption in children.

\section{References}

Birch, L. L., Fisher, J. O., Mackey, C. N., Grimm-Tomas, K., Sawyer, R., \& Johnson, S. L (2001). Confirmatory factor analysis of the child feeding questionnaire: a measure of parental attitudes, beliefs and practices about child feeding and obesity proneness. Appetite, 36, 201-210.

Bönnhoff, N., Eissing, G., Baumann, T., \& Kuß, S. (2002). Steigerung des Obst und Gemüseverzehrs bei Grundschulkindern. Ernährungsumschau, 49, 340-343.

Brown, R., \& Ogden, J. (2004). Children's eating attitudes and behaviour: a study of the modelling and control theories of parental influence. Health Education Research, 19, 261-271.

Dutch Food Consumption Survey. (1998). Zo eet Nederland 1998. Resultaten van de Voedsel Consumptie Peiling 1997-1998. The Hague: Voedingscentrum.

Epstein, L. H., Gordy, C. C., Raynor, H. A., Beddome, M., Kilanowski, C. K., \& Paluch, R. (2001). Increasing fruit and vegetable intake and decreasing fat and sugar intake in families at risk for childhood obesity. Obesity Research, 9, 171-178.

Galloway, A. T., Fiorito, L. M., Lee, Y., \& Birch, L. L. (2005). Parental pressure, dietary patterns, and weight status in girls who are 'picky eaters'. Journal of the American Dietetic Association, 105, 541-548.

Guerrieri, R. (2005). Toen de koekjestrommel de fruitschaal verdrong. ..: de toxische omgeving als oorzaak van obesitas. Psycholoog, 40, 642-646.

Health-Council-of-the-Netherlands. (2002). Voedingsnormen energie, eiwitten, vetten en verteerbare koolhydraten. Den Haag.

Hearn, N., Baranowski, T., Baranowski, J., Doyle, C., Smith, M., Lin, L. S., et al. (1998). Environmental influences on dietary behavior among children: availability and accessibility of fruits and vegetables enable consumption. Journal of Health Education, 29, 26-32.

Hung, H. C., Joshipura, K. J., Jiang, R., Hu, F. B., Hunter, D., Smith-Warner, S. A., et al. (2004). Fruit and vegetable intake and risk of major chronic disease. Journal of the National Cancer Institute, 96, 1577-1584.

Jansen, E., Mulkens, S., \& Jansen, A. (2007). Do not eat the red food! Prohibition of snacks leads to their relatively higher consumption in children Appetite, 49, 572577.

Jansen, E., Mulkens, S., Emond, Y., \& Jansen, A. (2008). From the Garden of Eden to the land of plenty: restriction of fruit and sweets intake leads to more fruit and sweets consumption in children. Appetite, 51, 570-575.

McCrory, M. A., Fuss, P. J., McCallum, J. E., Yao, M., Vinken, A. G., Hays, N. P., et al. (1999). Dietary variety within food groups: association with energy intake and body fatness in men and women. American Journal of Clinical Nutrition, 69, 440-447.

Piaget, J. (1965). The moral judgement of the child. New York: Free Press.

Roblin, L. (2007). Childhood obesity: food, nutrient, and eating-habit trends and influences. Applied Physiology, Nutrition, and Metabolism, 32, 635-645.

van den Hurk, K., van Dommelen, P., de Wilde, J. A., Verkerk, P. H., van Buuren, S., \& HiraSing, R. A. 2006. Prevalentie van overgewicht en obesitas bij jeugdigen 4-15 jaar in de periode 2002-2004. TNO-rapport $\mathrm{KvL} / \mathrm{JPB} / 2006.010$. 